\title{
Journal of Diabetes and Metabolism
}

\section{Serum and Urinary Nitrites and Nitrates and Doppler Sonography in Detection of Early Diabetic Complications}

Mohamed Abo El Asrar ${ }^{1}$, Amira A.M. Adly $^{1 *}$, Eman El Hadidi ${ }^{2}$ and Mohamed Gharib ${ }^{3}$

${ }^{1}$ Pediatric, Clinical Pathology Department, Cairo, Egypt

${ }^{2}$ Clinical Pathology Department, Cairo, Egypt

${ }^{3}$ Radiodiagnosis Department, Cairo, Egypt

\begin{abstract}
Objective: to evaluate serum and urinary nitrite and nitrate concentrations as an index of nitric oxide (NO) production in type1diabetes mellitus (T1DM) and to investigate the possible alteration and correlation with intra renal Doppler resistive indexes (RIs).

Design: The study included 90 children and adolescent with T1DM divided into 2 groups: Group 1: included 45 prepubertal type1 diabetics who were defined as Tanner stage1. Their age ranged between 8-14 years. Group 2: included 45 pubertal type diabetics who were defined as Tanner stages 2-5. Their ages ranged between 15-19 years. They were compared to 45 age and sex matched healthy controls. Clinical examination was done. Laboratory investigations included; post-prandial blood glucose (PPBG), glycosylated heamoglobin (HbA1C), Fundus examination, urinary microalbumin and measurement of serum and urinary nitrite and nitrate levels. Doppler ultrasonographic registration of intrarenal Rls were performed.

Results: Compared to controls, both diabetic groups had significantly increased concentrations of serum ( $P=0.001)$ and urinary NO $(P=0.008)$. Doppler Rls values were significantly elevated in both diabetic groups compared to controls $(P<0.001)$.A significant positive correlation was found between serum and urinary NO levels $(P<0.001)$. Serum NO was positively correlated with Doppler RIs $(P=0.002)$, HbA1c $(P=0.012)$, PPBG $(P=0.000)$ and diabetes duration $(P=0.004)$. Doppler RIs were positively correlated with mean HbA1c $(P=0.025)$, PPBG $(P=0.001)$ and diabetes duration $(P=0.000)$.

Conclusion: In type 1 diabetes chronic hyperglycemia may act through a mechanism that involves increased NO production or action and contributes to generating intrarenal hemodynamic abnormalities which could be detectable by Doppler ultrasonography even before overt clinical nephropathy. Further follow up studies are needed to document the usefulness of Doppler ultrasound in detection of preclinical nephropathy.
\end{abstract}

\section{Introduction}

Clinically evident diabetes-related microvascular complications are rare in childhood and adolescence. Nonetheless, early functional and structural abnormalities may be present a few years after the onset of the disease [1]. Chronic hyperglycemia is central in the pathophysiology of microangiopathy and in the evolution of diabetes microvascular complications. It sets in motion a series of biochemical disturbances in critical tissues, including the kidney, leading to functional changes followed by irreversible structural changes, and finally to clinical disease [2]. Hyperglycemia is associated with excessive free radical generation and oxidant stress. Oxidant stress may be linked to diabetes via altered $\mathrm{NO}$ production and action [3]. NO, an endothelium-derived relaxing factor is a pleiotropic intercellular messenger regulating many cellular functions [4]. Microalbuminuria, a precursor of diabetic nephropathy is associated with a generalized endothelial vascular dysfunction [5]. In this regard, glucose dependent abnormality in nitric oxide (NO) production and action has postulated to occur in early diabetic nephropathy [6]. Vasodilation due to increased NO generation or action has recently beenimplicated in the pathogenesis of glomerular hyperfiltration and in the enhanced permeability that leads to microalbuminuria [7]. In a rat model of streptozotocin-induced diabetes, the plasma and urinary excretion levels of stable products of NO oxidation were higher than controls, suggesting a generalized increase in NO synthesis. NO decomposes very rapidly in biological solutions into more stable nitrite (NO2-) and nitrate (NO- [8], which can be analyzed in serum as indicators of $\mathrm{NO}$ activity in vivo [9].

Doppler ultrasonography is a noninvasive method for investigating renal hemodynamic. The RI calculated as :[( peak systolic velocity _ peak diastolic velocity)/peak systolic velocity] determined by
Doppler ultrasonography reflects intrarenal vascular resistance [10]. Increased intrarenal RI has recently been shown in adults with diabetic nephropathy as a function of creatinine clearance [11]. However, data on RI in children with diabetes are still lacking, and the correlation between increased intrarenal RI and altered renal hemodynamics remains unclear. The aim of the present study was (a) to evaluate serum and urinary NO concentrations in children and adolescents with type1 diabetes mellitus compared with age-matched healthy subjects (b) to find out whether Doppler ultrasonography could be used to detect early changes in renal RIs and to correlate it with metabolic parameters and NO concentrations.

\section{Patients and Methods}

We studied 90 children and adolescents with type 1 diabetes mellitus, diagnosed based on a previous history of diabetes or fulfillment of World Health Organization criteria [12]. Patients with

*Corresponding author: Amira A.M. Adly, Pediatric Department, Cairo, Egypt, E-mail: amiradiabetes@yahoo.com

Received October 06, 2010; Accepted January 20, 2011; Published January 24 2011

Citation: El Asrar MA, Adly AAM, El Hadidi E, Gharib M (2011) Serum and Urinary Nitrites and Nitrates and Doppler Sonography in Detection of Early Diabetic Complications. J Diabetes Metab 2:117. doi:10.4172/2155-6156.1000117

Copyright: (c) 2011 El Asrar MA, et al. This is an open-access article distributed under the terms of the Creative Commons Attribution License, which permits unrestricted use, distribution, and reproduction in any medium, provided the original author and source are credited. 


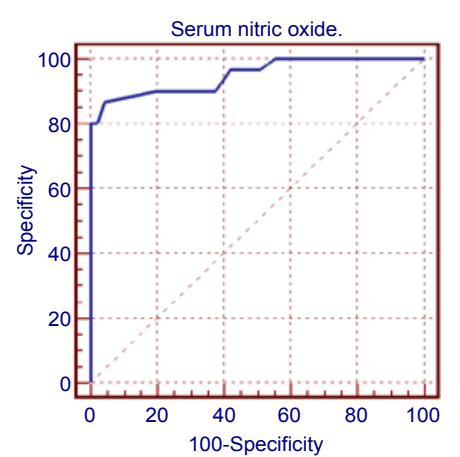

Figure 1a: Sensitivity and specificity of serum nitric oxide.

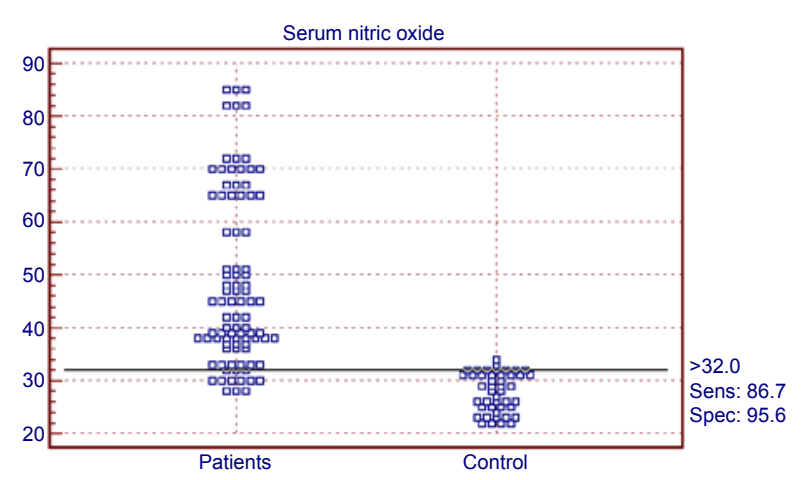

Figure 1b: Cutoff point between patients and controls as regards serum nitric oxide.

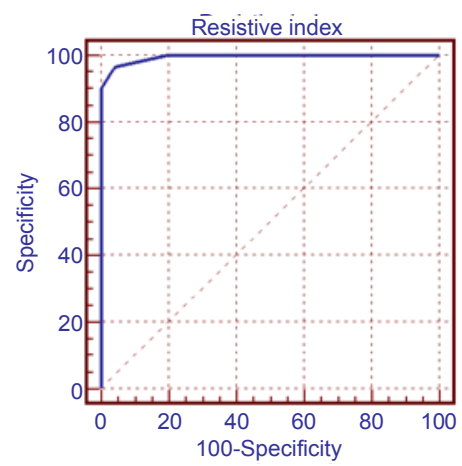

Figure 2a: Sensitivity and specificity of mean RI.

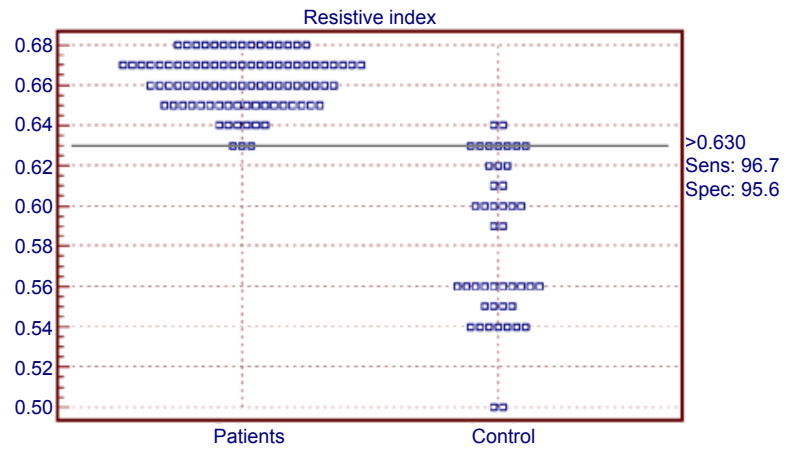

Figure 2b: Cutoff point between patients and control as regards mean RI.

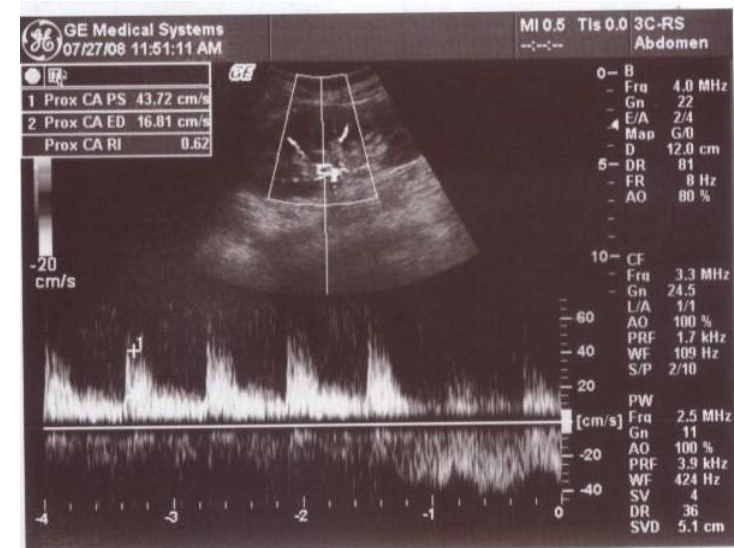

Doppler U/S of the right kidney in a case of group $1 . \mathrm{Rl}=0.62$

(a)

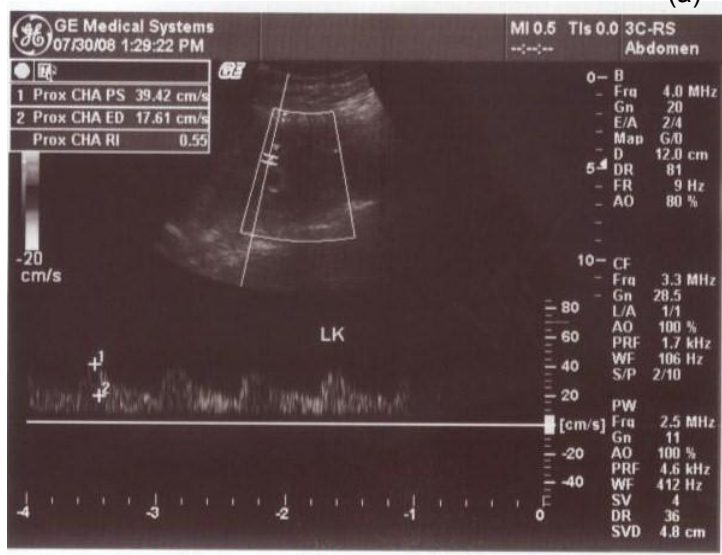

Doppler U/S of the left kidney in a case of group 3 (control). Rl=0.55 (b)

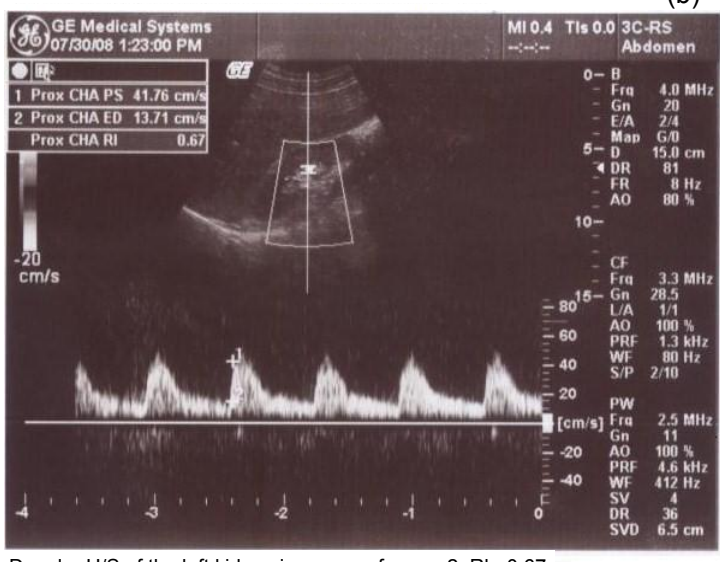

Doppler U/S of the left kidney in a case of group 2 . Rl= 0.67

(c)

Figure (3): Doppler U/S of the kidney showing resistive index of the renal artery of prepubertal diabetic(a0,normal control (b) and pubertal diabetic patients(c).

known renal arterial stenosis, or those with malignancy or systemic disorders, were excluded. The study protocol was approved by the local ethical committee. Studied patients were recruited from the regular attendants of the Pediatric Diabetes Clinic, Children's Hospital, Ain Shams University between October 2009 and September 2010. They were divided into two groups according to their pubertal staging (breast development in girls and genital development in boys according to the criteria of Tanner [13]).

Group 1: included 45 prepubertal Tanner stage1children (33 females and 12 males) with type $1 \mathrm{DM}$. 


\begin{tabular}{|c|c|c|c|c|c|c|c|c|c|c|}
\hline \multirow{2}{*}{ Variable } & \multicolumn{3}{|c|}{ Group $1(n=45)$} & \multicolumn{3}{|c|}{ Group $2(n=45)$} & \multicolumn{3}{|c|}{ Control Group $(n=45)$} & \multirow{2}{*}{ P-value } \\
\hline & Range & Mean & SD & Range & Mean & SD & Range & Mean & SD & \\
\hline Age (year) & $8-14$ & 12.6 & 1.8 & $15-19$ & 16.4 & 1.8 & $8-19$ & 13.7 & 2.9 & $<0.001$ \\
\hline Weight (kg) & $18-66$ & 36.3 & 13.5 & $35-75$ & 51.7 & 11.0 & $27-66$ & 42.5 & 12.4 & 0.005 \\
\hline Hieght (cm) & $106-162$ & 134.4 & 14.7 & $137-170$ & 154.3 & 10.0 & $135-170$ & 149.5 & 10.8 & $<0.001$ \\
\hline BMI (kglm2) & $17-44$ & 26.5 & 7.7 & $25.5-46.9$ & 33.3 & 5.6 & $20-38.8$ & 28.1 & 6.5 & 0.019 \\
\hline Duration of DM (year) & $1-5$ & 2.8 & 1.5 & $2-13$ & 6.4 & 3.9 & -- & ------- & ------- & 0.002 \\
\hline $\mathrm{SBP}(\mathrm{mmHg})$ & $100-115$ & 109.3 & 4.7 & 98.125 & 116.1 & 6.0 & $100-120$ & 110.1 & 7.5 & 0.170 \\
\hline $\mathrm{DBP}(\mathrm{mmHg})$ & $65-75$ & 69.3 & 3.9 & $65-90$ & 75.2 & 5.2 & $64-80$ & 70.3 & 7.7 & 0.083 \\
\hline PPBG(mgldl) & $110-443$ & 176.3 & 86.8 & $127-299$ & 168.2 & 44.8 & -- & ------- & ------- & 0.75 \\
\hline Hb A1C \% & $8-13.5$ & 9.9 & 1.5 & $8-12.4$ & 9.9 & 1.2 & -- & -------- & -------- & 0.97 \\
\hline Serum NO(mmollL) & $30-82$ & 48.2 & 15.8 & $28-85$ & 48.7 & 17.3 & $22-35$ & 27.6 & 3.5 & $<0.001$ \\
\hline Urine $\mathrm{NO}$ (mmollL) & $99-300$ & 181.5 & 51.3 & $85-350$ & 173.6 & 67.1 & $75-135$ & 94.1 & 17.1 & $<0.001$ \\
\hline
\end{tabular}

Table 1: Comparison between the three studied groups as regards demographic and clinical data (ANOVA test).

Group 2: included 45 pubertal children and adolescents (Tanner stages 2-5) with type1 DM. Their ages ranged between 15 to 19 years with a mean of $16.4 \pm 1.8$. They were 33 females and 12 males.

Another group of 45 healthy subjects ( 33 females and 12 males) matched for age and sex served as controls. Their age ranged between 8 to 19 years with a mean of $13.7 \pm 2.9$.

\section{Inclusion criteria}

None of the studied diabetic groups had clinical signs or laboratory evidence of kidney disease or microalbuminuria or were affected by other diabetic microvascular complications as diabetic retinopathy (evaluated by stereoscopic Fundus photography) or neuropathy (evaluated by nerve conduction velocity and autonomic tests). Patients with other autoimmune diseases, taking other medications than insulin or those with urinary tract infection at time of urinary sample collection were excluded.

Methods: All patients and controls were subjected to the following:

1-Detailed history taking stressing on demographic data, disease duration, and insulin therapy (regarding type, dose and frequency) were collected.

Files were reviewed for the presence of hypertension, microalbuminuria and diabetic retinopathy.

2-Through clinical examination with particular emphasis on: anthropometric measures. Body weight was measured with a digital scale to the nearest $0.1 \mathrm{~kg}$, and height was measured in triplicate with a wall-mounted stadiometer. The body mass index (BMI) was defined as weight in kilograms divided by the square of the height in meters). Pubertal assessment and staging using Tannar classification was done.

Blood pressure was measured with a standard mercury sphygmomanometer, in a quite and comfortable environment, after 3-5 minutes of rest. The cuff size was appropriate for the size of the $40 \%$ of the arm circumference midway between the olecranon and the acromion according to the recommendations of the Task Force on Blood Pressure Control in Children [14].

\section{3-Laboratory investigations}

Post-Prandial Blood Glucose (PPBG): Using glucose oxidase method with calculation of the mean values over the last year prior to the study. Glycosylated hemoglobin (HbAlc): Blood samples were collected in fasting condition and immediately centrifuged at $4^{\circ} \mathrm{C}$. $\mathrm{HbAlc}$ concentrations were measured every 3 months using a highperformance liquid chromatography method (Diamat analyzer; BioRad, Richmond, CA). The normal range was $4.2-6.0 \%$, with an interassay coefficient of variation (CV) of $3 \%$. All the patients had at least 3 determinations per year, and the mean of these determinations was used for statistical analysis. Quantitative determination of urinary microalbumin for diabetic nephropathy. Microalbuminuria was defined as excretion rate of albumin $30-300 \mathrm{mg} /$ urinary creatinine.

Measurement of serum and urinary nitrate and nitrite by colorimetric assay.

Serum $\mathrm{NO}^{-}+\mathrm{NO}^{-}$levels were measured in triplicate by the conversion of $\mathrm{NO}^{-}$to $\mathrm{NO}^{-}$by a commercially available kit based on the Griess reaction (active motif's NO quantitation kit), following the manufacturer's instructions. Blood samples were collected in fasting conditions, and serum nitrite $\left(\mathrm{NO}^{-}\right)$and nitrate $\left(\mathrm{NO}^{-}\right)$ concentrations were measured [15].

In the cell, NO undergoes a series of reactions with several molecules present in biological fluids and is eventually metabolized to nitrite $\left(\mathrm{NO}^{-}\right)$and nitrate $\left(\mathrm{NO}^{-}\right)$. Thus, the best index of total NO production is the sum of both nitrite and nitrate, commonly quantified in a two step assay [16].

NO urinary metabolites were evaluated in the overnight urine collection; for each patient, $50 \mu \mathrm{l}$ antioxidant solution was added to 40 $\mathrm{ml}$ fresh overnight urine \& urine and frozen at $-20^{\circ} \mathrm{C}$. Nitrite $\left(\mathrm{NO}^{-}\right)$ and nitrate $\left(\mathrm{NO}^{-}\right)$contents were evaluated with the nitrate reductase method. The children's eating habits reflect the typical Mediterranean diet. Consumption of foods containing nitrates (e.g., spinach, beets, cabbage, cauliflower, beetroot, and lettuce) was discouraged for the 48 $\mathrm{h}$ preceding the measurements to avoid the dietary influence of $\mathrm{NO}$ assay. Consumption of foods containing nitrates (e.g., spinach, beets, cabbage, cauliflower, beetroot, and lettuce) was discouraged for the $48 \mathrm{~h}$ preceding the measurements to avoid the dietary influence of $\mathrm{NO}$ assay.

\section{Doppler ultrasound evaluation}

The measurements were commenced in patients fasting for at least $8 \mathrm{~h}$, after recording pulse and blood pressure. All the examinations were performed using a 3.5- $4.0 \mathrm{MHz}$ vector array transducer, after 15 min rest in a horizontal position [17]. The first measurement was the size of the left and right kidney. The main trunk of the renal artery was displayed using color Doppler ultrasonography. Three measurements each were taken within $5 \mathrm{~min}$ in the vicinity of the interlobary artery at the boundary of the center of the kidney and the upper and lower pole using pulsed Doppler.

The RI, according to Pourcelot, was calculated on the basis of the following formula:

[(peak systolic velocity_peak diastolic velocity)/peak systolic velocity]. The average value of three bilateral measurements was taken for statistical analysis. All the examinations were performed twice by the same operator, without knowledge of the patient group (case or control).

\section{Statistical analysis}

All values are expressed as means $\pm \mathrm{SD}$. Differences in unpaired 
samples were examined by Mann-Whitney testing. ANOVA test for comparison between the three quantitative values. $P$ value of 0.05 was considered statistically significant. Correlation between variables was evaluated using Pearson's correlation coefficient. Data input and basic evaluation were carried out using the SPSS version 10.0 software.

\section{Results}

The descriptive data of the studied groups are presented in (Table 1). Studied diabetic groups were comparable as regards their mean PPBG, HbA1c, systolic blood pressure $(p>0.05)$, although mean diastolic blood pressure was higher in pubertal diabetics, this did not reach a statistical significance $(75.2 \pm 5.2$ versus $69.3 \pm 3.9 \mathrm{mmHg})$.

Pubertal diabetic patients were older and had longer duration of illness compared to pre-pubertal diabetics. Weight, height and BMI values were significantly higher in pubertal diabetics compared to other groups.

Both prepubertal and pubertal diabetics had significantly elevated serum and urinary $\mathrm{NO}$ levels compared to controls (mean serum NO; 48.215.8 \pm , 48.7 17. \pm 3 and $27.6 \pm 3.5 \mathrm{mmo} / \mathrm{l}$ respectively, $\mathrm{p}<0.001$, mean urinary NO; $181.55 \pm 1.3,173.6 \pm 27.6$ and $94.1 \pm 17.1 \mathrm{mmol} / \mathrm{l}$ respectively, $\mathrm{p}<0.001)$. Serum $\mathrm{NO}$ was positively correlated with urinary NO2-+NO3- levels $(\mathrm{P}<0.001, \mathrm{r}=0.795)$, mean $\mathrm{RI}(\mathrm{P}=0.002$, $\mathrm{r}=0.536), \mathrm{HbAlc}(\mathrm{P}=0.012, \mathrm{r}=0.452), \mathrm{PPBG}(\mathrm{P}<0.000, \mathrm{r}=0.616)$, and diabetes duration $(\mathrm{P}=0.004, \mathrm{r}=0.505)$.

The renal RIs of both right and left kidney were significantly elevated in diabetics compared to controls. These findings occurred in both pre-pubertal and pubertal diabetics with RI of right kidney $(0.66 \pm 0.01,0.661 \pm 0.017$ and $0.593 \pm 0.021, \mathrm{p}<0.001$ respectively $)$ and the RI of left kidney $(0.65 \pm 0,017,0.65 \pm 0.019$ and $0.59 \pm 0.015$ respectively, $\mathrm{p}<0.001)$.Similarly the mean RI was elevated in both diabetic groups compared to controls $(0.66 \pm 0.01,0.65 \pm 0.015$ and $0.59 \pm 0.01$ respectively, $\mathrm{p}<0.001)$ table $(2)$.

When a correlation analysis was done, the mean RI was correlated positively with $\operatorname{HbA1C}(\mathrm{P}=0.025, \mathrm{r}=0.062), \mathrm{PPBG}(\mathrm{P}=0.0001, \mathrm{r}=$ 0.682 ), and diabetes duration $(P=0.000, r=0.608)$, table (3). A Receiver Operating Characteristic curve was done and it identify a cut off value for serum $\mathrm{NO}$ of $32 \mathrm{mmol} / \mathrm{l}$ between diabetic patients and controls with sensitivity of $86.7 \%$ and specificity of $95.6 \%$. Although a cut off value of RI equal to 0.62 with a sensitivity of $96.7 \%$ and specificity of $95.6 \%$ was detected between patients and controls table (4).

\section{Discussion}

The present study demonstrates increase in both serum and urinary NO levels in diabetics with no evidence of microvascular complications. Early diabetes is often accompanied by an increased glomerular filtration rate (GFR) and hyperfiltration which is significantly dependent upon increased NO activity and contributes to progression of diabetic nephropathy (9). Diabetes triggers mechanisms that in parallel enhance and suppress NO bioavailability in the kidney. During the early phase of nephropathy the balance between these two opposing forces is shifted toward NO production $[18,19]$. This plays a pivotal role in the development of characteristic hemodynamic changes and may contribute to consequent structural alteration in the glomeruli [20].

Nonetheless, alterations of the NO system in the diabetic kidney and their role in the pathophysiology of diabetic nephropathy still represent a complex and controversial scenario as many important mechanisms can co-modulate NO activity (e.g., glycemic control, insulin treatment, duration of the disease, development of diabetes complications) [21, 22]. Early nephropathy is associated with increased intrarenal NO production mediated primarily by constitutively released NO (endothelial nitric oxide synthase [eNOS] and neuronal nitric oxide synthase [nNOS])[23].

In the present study, serum and urinary NO levels were found to be significantly increased in diabetics compared to controls. This was detected in prepubertal and pubertal diabetics, showing that enhanced NO production occur even before microalbuminuria appears, and is independent from diabetes duration and puberty [24]

Puberty accelerates microvascular complications although prepubertal years of hyperglycemia appear to contribute to its development $[25,26]$.

Puberty accelerates diabetic microvascular complications including nephropathy. Animal studies confirm a different renal hypertrophic response to diabetes before and after puberty, probably due to differences in the production of transforming growth factors (TGF) [27] Complex physiological changes during puberty could affect potentially pathogenic mechanisms of diabetic kidney disease. Increased blood pressure, activation of the growth hormone-insulin-like growth factor I axis, and production of sex steroids could all play a role in pubertal susceptibility to diabetic renal hypertrophy and nephropathy. Normal changes during puberty, when coupled with diabetes and superimposed

\begin{tabular}{|c|c|c|c|c|c|c|c|c|c|c|}
\hline & \multicolumn{3}{|c|}{ Group $1 \mathrm{~N}=45$} & \multicolumn{3}{|c|}{ Group $2 \mathrm{~N}=45$} & \multicolumn{3}{|c|}{ Control Group $n=45$} & \multirow{2}{*}{$P$ value } \\
\hline & Range & Mean & SD & Range & Mean & SD & Range & Mean & SD & \\
\hline Serum NO (MmollL) & $30-82$ & 48.200 & 15.830 & $28-85$ & 48.667 & 17.332 & $22-35$ & 27.533 & 3.502 & $<0.001$ \\
\hline Urine NO (MmollL) & $99-300$ & 181.467 & 51.289 & $85-350$ & 173.600 & 67.092 & $75-135$ & 94.067 & 17.077 & $<0.001$ \\
\hline RI of right kidney & $0.6-0.7$ & 0.665 & 0.016 & $0.6-0.7$ & 0.661 & 0.017 & $0.5-0.6$ & 0.593 & 0.021 & $<0.001$ \\
\hline RI of left kidney & $0.6-0.7$ & 0.658 & 0.017 & $0.6-0.7$ & 0.657 & 0.019 & $0.5-0.6$ & 0.592 & 0.015 & $<0.001$ \\
\hline Mean resistive index & $0.64-0.68$ & 0.661 & 0.012 & $0.63-0.68$ & 0.659 & 0.015 & $0.57-0 . .62$ & 0.592 & 0.015 & $<0.001$ \\
\hline
\end{tabular}

Table 2: Comparison between the three studied groups regarding their serum and urine nitric oxide and renalresistive indexes(ANOVA test)

\begin{tabular}{|c|c|c|c|c|}
\hline & \multicolumn{2}{|c|}{ Mean resistive index } & \multicolumn{2}{|c|}{ Serum nitric oxide (mmol/l) } \\
\hline & $\mathbf{r}$ & P-value & $\mathbf{r}$ & P-value \\
\hline Serum nitric oxide $(\mathrm{mmol} / \mathrm{l})$ & 0.536 & $0.002^{*}$ & & \\
\hline Age (years) & -0.132 & 0.488 & -0.031 & 0.873 \\
\hline Duration (years) & 0.608 & $0.000^{*}$ & 0.505 & $0.004^{*}$ \\
\hline Mean PPBG (mg/dl) & 0.682 & $0.000^{*}$ & 0.616 & $0.000^{*}$ \\
\hline Mean $\mathrm{HbA}_{1 c}(\%)$ & 0.062 & $0.025^{*}$ & 0.452 & $0.012^{*}$ \\
\hline Urinary nitric oxide $(\mathrm{mmol} / \mathrm{l})$ & 0.577 & $<0.001^{*}$ & 0.795 & $<0.001^{*}$ \\
\hline BMI $\left(\mathbf{k g} / \mathbf{m}^{2}\right)$ & -0.046 & 0.810 & -0.044 & 0.818 \\
\hline
\end{tabular}

Table 3: Correlation between mean resistive index and serum nitric oxide with studied variables in diabetic patients.

\begin{tabular}{|l|l|l|l|l|l|l|}
\hline Variable & Cut-off values & Sens. (\%) & Spec. (\%) & PPV. (\%) & NPV. (\%) & Accuracy (\%) \\
\hline Serum NO & $>32 \mathrm{mmol} / \mathrm{l}$ & 86.7 & 95.6 & 97.5 & 78.2 \\
\hline Mean RI & $>0.63$ & 96.7 & 95.6 & 95.4 & 95 & 94.4
\end{tabular}

Table 4: Cut-off values for serum NO and mean RI between patients and controls. 
on a genetically susceptible milieu, are capable of accelerating diabetic hypertrophy and microvascular lesions [26] Krolewski et al. [28] suggested that the prepubertal years were a protection from the development of diabetic nephropathy when they showed that patients with earlier onset of type 1 DM (DM1) had onset of nephropathy at a longer disease duration. Patients with younger onset required a longer duration of DM1 to develop nephropathy, even though the relative risk of developing nephropathy was eventually the same in all patients [29]. Because of these strong epidemiological studies, screening tests for retinopathy and nephropathy are not generally recommended until the process of sexual maturation has begun [30].

Blood pressure increases with age in normal children, as shown repeatedly in large national task-force studies [14]. While idiopathic hypertension may develop during puberty, most children with microalbuminuria remain normotensive [31]. It is possible that some critical, lower level of mean arterial pressure is necessary for microalbuminuria to develop [25]. The International Diabetic Nephropathy Study Group showed a correlation between higher blood pressures within the normal range and mesangial expansion in normoalbuminuric patients with DM1 [32]. Such subtle increases in arterial pressure may be of clinical importance in a condition like DM that results in abnormal autoregulation of pressure and flow in the kidney [33]. In the present study pubertal diabetics had higher blood pressure compared to pre- pubertal patients. Higher systolic blood pressure has been recognized as a risk factor for progression of microalbuminuria [25]

In contrast to our findings, some studies found elevated serum and urinary nitrites and nitrates in pubertal compared to prepubertal diabetics and attributed that to the worse metabolic control in this critical period [34].This could be explained by that both studied diabetic groups (before and after puberty) had poor metabolic control as evidenced by their high mean HbAlc.

Several studies have demonstrated that insulin sensitivity decreases early in puberty in patients with DM [35]. This begins between Tanner stage 1 (prepuberty) and Tanner stage 2, the earliest stage of puberty detectable on physical examination (breast buds, fine pubic hair, and testicular enlargement). Several studies have found a relationship between insulin sensitivity and the GH-IGF-I axis, suggesting an increased tissue GH effect as the cause of this phenomenon [25].

The diabetic state is associated with increases in the production of reactive oxygen molecules as well as alterations in the redox potential of cells [36,37]. In the kidney, generation of excess superoxide anion in this setting leads to nitric oxide consumption and protein tyrosine nitration [38]. These changes may further alter cellular function, through both altered function of the affected proteins and diminished nitric oxide bioavailability, with resulting consequences to vascular and epithelial function. Oxidative stress also activates PKC, which in turn produces increased TGF- production [39]. Histological, basal membrane thickening seems to have the major predictive value to estimate the risk of disease of diabetic nephropathy (2), but it is not practical to implement invasive methods for screening. Doppler ultrasonography is a reliable method for renal explorations by providing not only morphological but also physiological data with perfusion view $[40,41]$. Doppler RI is a useful parameter for quantifying the alteration in renal blood flow, it reflects intrarenal vascular resistance which is markedly linked to vascular compliance. Elevated RIs were reported with vascular-interstitial disease, including diabetic nephropathy which could be due to the decreased tissue and vascular compliance and to the increased renal vascular resistance [42].
In the present study we select the RIs as a method to detect early intrarenal abnormalities. Early functional and structural abnormalities present after a few years of diabetes might be responsible for the precocious alteration in renal hemodynamics, and might be reflected in increased RI $[43,44]$. Nonetheless, only few studies describing the application of Doppler ultrasonography in the evaluation of intrarenal hemodynamic abnormalities in diabetic nephropathy have been published, and most of them were performed in adults with type 1 or type 2 diabetes $[10,17]$

We aimed to assess whether Doppler ultrasonography could be used to detect changes in renal RI and intrarenal hemodynamics in young diabetics. The RI calculated from blood flow velocities in vessels reflects renovascular resistance and is known to increase in various disorders [44]. Ikee et al. [45] reported a direct relationship between RI and arteriolosclerosis in damaged kidneys [45].

We observed that diabetic patients had significantly increased values of Doppler RI compared to controls. This was found in the prepubertal and pubertal children with diabetes although all having normal renal function. Furthermore increased RI correlates positively with $\mathrm{AlC}$, duration of diabetes, and $\mathrm{NO}$ excretion.

The significant positive association between NO and Doppler RI in diabetics suggests that precocious abnormality in NO production and action occurring early in the diabetes course may have contributed to the loss of maintaining the normal state of vascular tone and thus to the higher RI values [46]. At the single-nephron level, diabetic hyperfiltration is characterized by disproportionately decreased afferent arteriolar resistance, resulting in elevated glomerular capillary pressure.

It has been reported that $\mathrm{NO}$ is important in the regulation of renal hemodynamics and, in particular, in maintaining the normal state of vascular tone [47]. An increased renal expression of endothelial cell NO synthase (NOS) and inducible NOS proteins has been found after 1 week in streptozotocin-induced diabetic rats $[48,49]$. This increased expression could be responsible for the attenuated tubuloglomerular feedback and the glomerular hyperfiltration observed in early diabetes.

In the present study we found a significant positive correlation between PPBG and HbAlc and both NO level and RIs. Hyperglycemia is directly related to renal hyperfiltration and hyperperfusion [50] and causally linked to vascular and glomerular dysfunction. A glucosedependent abnormality in NO production and action has recently been the subject of extensive investigation. Similarly Chiarelli et al [19] reported that; HbAlc was significantly and positively related to serum NO and GFR values suggesting that chronic hyperglycemia may act through a mechanism that involves increased NO generation and/ or action [51]. Prolonged exposure of endothelial cells to high glucose increases both NO and superoxide anion production. Expression of NO action largely depends on its relative levels and on its interaction with superoxide anions. Thus, we hypothesize that in our patients with no clinical evidence of nephropathy, NO production overcomes $\mathrm{NO}$ degradation by superoxide anions which favors renal vasodilatation. However, it has recently been shown that when peroxynitrite- a potent cytotoxic species generated by the interaction of $\mathrm{NO}$ with superoxideis present in small amounts, it is able to induce vasodilation via thiol-dependent formation of NO [39]. Elevated levels of serum and urinary nitrites and nitrates were correlated with diabetes duration as well as parameters of metabolic control. Studies have shown that good metabolic control (GC) is beneficial in slowing the progression of nephropathy in diabetes, and if the duration of poor metabolic control (PC) is prolonged before reinstitution of GC, nephropathy is 
not reversed. hyperglycemia-induced oxidative stress and NO can be prevented if GC is initiated early[52]. In the same way ; Chiarelli et al. [19] reported that the significant correlation between HbAlc and serum $\mathrm{NO}^{-}+\mathrm{NO}^{-}$content confirms that poor glycemic control may directly influence NO synthesis. This correlation was observed in both normoalbuminuric and microalbuminuric adolescents, suggesting that NO production is increased early in the natural course of diabetes and independently of the presence of microvascular complications. The strong correlation between serum NO and GFR and AER observed only in microalbuminuric patients supports the hypothesis that longterm poor metabolic control leads to glomerular hyperfiltration and persistent microalbuminuria, possibly by NO-mediated changes in glomerular vascular tone [53].The researchers measured the Doppler RIs in the interlobular renal arteries of all 83 study participants and found that diabetics had significantly higher values than their agematched controls. The renal Doppler RIs also correlated positively with diabetes duration. They concluded that Doppler sonography can be used to detect early changes in the hemodynamics of pediatric diabetics before any clinical indicators of kidney problems are evident [54]. An important finding was the positive and significant correlation between NO levels and the RIs which represent the early hemodynamic intrarenal changes. The observations of Palm et al. [3] should fuel future studies that focus on the interaction of $\mathrm{NO}$ and $\mathrm{O} 2$ availability, as well as the effects of NO on mitochondrial respiration and HIF-dependent responses, during the early stages of diabetes in the renal medulla. These processes associated with renal medullary hypoxia may interact in an additive or synergistic manner with the hemodynamic events that evoke glomerular hyperfiltration. In conclusion, this study demonstrates that in type 1 diabetes, chronic hyperglycemia may act through a mechanism that involves increased NO production and/or action and contributes to generating intrarenal hemodynamic abnormalities, detectable by Doppler ultrasonography even in early diabetic nephropathy before microalbuminuria appears, and acts independently from puberty. Although our data have to be confirmed in further longitudinal studies, it is suggested that evaluation of NO excretion and Doppler intrarenal RI may be a useful complementary test in the evaluation of early stages of diabetic kidney disease. Longitudinal monitoring of these parameters may better define their relevance in progressive kidney disease and provide greater insight into the mechanisms underlying this process.

\section{References}

1. Atkins RC, Zimmet $P$ (2010) Diabetic kidney disease: act now or pay later. Nephrology 15: 20-22.

2. Chiarelli F, Mohn A (2002) Angiopathy in children with diabetes. Minerva Pediatr 54: 187-201.

3. Palm F, Friederich M, Carlsson PO, Hansell P, Teerlink T, et al. (2008) Reduced nitric oxide in diabetic kidneys due to increased hepatic arginine metabolism: Implications for renomedullary oxygen availability. Am J Physiol Renal Fluid Electrolyte Physiol 294: F30-37

4. Pelliccia P, Schiavone C, Primavera A, Tumini S, Mohn A, et al. (2006) Serum and urinary nitrites and nitrates and Doppler sonography in children with diabetes. Diabetes Care 29: 2676-2681.

5. Barıs N, Erdog M, Sezer E, Saygılı F, Mert Ozgonul A, et al. (2009) Alterations in L-arginine and inflammatory markers in type 2 diabetic patients with and without microalbuminuria. Acta Diabetol 46: 309- 316

6. Palm F, Hansell P, Ronquist G, Waldenstrom A, Liss P, et al. (2004) Polyolpathway-dependent disturbances in renal medullary metabolism in experimental insulin deficient diabetes mellitus in rats. Diabetologia 47: 12231231.

7. Van Rensburg BW (2007) Diabetes and chronic kidney disease. CME 25: 368370
8. Marletta MA, Yoon PS, lyengar R, Leaf CD, Wishnok JS (1988) Macrophage oxidation of L-arginine to nitrite and nitrate: nitric oxide is an intermediate. Biochemistry 27:8706-8711.

9. Levine DZ (2006) Hyperfiltration, nitric oxide, and diabetic nephropathy. Curr Hypertens Rep 8: 153-157.

10. Ohta Y, Fujii K, Arima H, Matsumura K, Tsuchihashi T et al. (2005) Increased renal resistive index in atherosclerosis and diabetic nephropathy assessed by Doppler sonography. J Hypertens 23: 1905-1911.

11. Radermacher J (2006) Resistive index: an ideal test for renovascular disease or ischemic nephropathy? Nat Clin Pract Nephrol 2: 232-233.

12. World Health Organization (1985) Diabetes Mellitus: Report of a WHO Study Group. World Health Organ Tech Rep Ser 727: 1-113.

13. Tanner JM (1975) Growth and endocrinology of the adolescent. In Endocrine and Genetic Diseases of Childhood. 2nd ed. Gardner L, Ed. Philadelphia and LondonLondon, WB Saunders: p 109-126.

14. Update on the 1987 Task Force on High Blood Pressure in Children and Adolescents: a working group report from the National High Blood Pressure Education Program: National High Blood Pressure Education Program Working Group on Hypertension Control in Children and Adolescents. (1996) Pediatrics 98: 649-658.

15. Green LC, Wagner DA, Glogowski L (1982) Analysis of nitrate, nitrite and [15N] nitrate in biological fluids. Anal Biochem 126: 131-138.

16. Moshage $H$, Kok B, Huizenga JR, Jansen PL (1995) Nitrite and nitrate determinations in plasma: a critical evaluation. Clin Chem 41: 892-896.

17. Frauchiger B, Nussbaumer P, Hugentobler M, Staub D (2000) Duplex sonographic registration of age and diabetes-related loss of renal vasodilatatory response to nitroglycerine. Nephrol Dial Transplant 15: 827-832.

18. Bank N, Aynedjian HS (1993) Role of EDRF (nitric oxide) in diabetic renal hyperfiltration. Kidney Int 43: 1306-1312.

19. Chiarelli F, Cipollone F, Romano F, Tumini S, Costantini F, et al. (2000) Increased circulating nitric oxide in young patients with type 1 diabetes and persistent microalbuminuria: relation to glomerular hyperfiltration. Diabetes 49 : 1258-1263.

20. Komers R, Anderson S (2003) Paradoxes of nitric oxide in the diabetic kidney. Am J Physiol Renal Physiol 284: F1121-F1137.

21. Larkins RG, Dunlop ME (1992) The link between hyperglycemia and diabetic nephropathy. Diabetologia 35: 499-504

22. Lo HC, Lin SC, Wang YM (2004) The relationship among serum cytokines, chemokine, nitric oxide, and leptin in children with type 1 diabetes mellitus. Clin Biochem 37: 666-672.

23. Prabhakar SS (2004) Role of nitric oxide in diabetic nephropathy. Semin Nephrol 24: 333-344

24. O'Connor AS and Schelling JR (2005) Diabetes and the kidney. Am J Kidney Dis 46: 766-773.

25. Lane PH (2002) Diabetic kidney disease: impact of puberty. Am J Physiol Rena Physiol 283: F589-F600.

26. Rudberg S, Ullman E, Dahlquist G (1998) Relationship between early metabolic control and the development of Microalbuminuria: A longitudinal study in children with type 1 (insulin-dependent) diabetes mellitus. Diabetologia 36:1309-1314

27. Lane P, Snelling DM, Hollman A, Langer WJ (2001) Puberty permits increased expression of renal transforming growth factor- 1 in experimental diabetes. Pediatr Nephrol 16: 1033-1039.

28. Krolewski AS, Warram JH, Christlieb AR, Busick EJ, Kahn CR (1985) The changing natural history of nephropathy in type I diabetes. Am J Med 78: 785794.

29. Lawson ML, Sochett EB, Chait PG, Balfe JW, Daneman D (1996) Effect of puberty on markers of glomerular hypertrophy and hypertension in IDDM. Diabetes 45: 51- 55

30. American Diabetes Association (2002) Diabetic nephropathy. Diabetes Care 25: S85-S89.

31. Osterby R, Bangstad HJ, Rudberg S (2000) Follow-up study of glomerula dimensions and cortical interstitium in microalbuminuric type 1 diabetic patients 
Citation: El Asrar MA, Adly AAM, El Hadidi E, Gharib M (2011) Serum and Urinary Nitrites and Nitrates and Doppler Sonography in Detection of Early Diabetic Complications. J Diabetes Metab 2:117. doi:10.4172/2155-6156.1000117

with or without antihypertensive treatment. Nephrol Dial Transplant 15: 16091616.

32. Drummond K, Mauer SM (2002) The early natural history of nephropathy in type 1 diabetes. II. Early renal structural changes in type 1 diabetes. Diabetes 51: 1580-1587.

33. Pelliccia P, Savino A, Cecamore C, Primavera A, Schiavone C, et al. (2008) Early changes in renal hemodynamics in children with Diabetes: Doppler Sonographic findings. Journal of Clinical Ultrasound 36: 335-340.

34. Mortensen, HB, and Hougaard P (1997) Comparison of metabolic control in a cross- sectional study of 2,873 children and adolescents with IDDM from 18 countries. Hvidore Study Group on Childhood Diabetes. Diabetes Care 20: 714-720.

35. Goran MI, Gower BA (2001) Longitudinal study on pubertal insulin resistance. Diabetes 50: 2444-2450.

36. Forbes JM, Coughlan MT, Cooper ME (2008) Oxidative stress as a major culprit in kidney disease in diabetes. Diabetes 57:1446-1454.

37. Yaqoob M, Patrick AW, McClelland P, Stevenson A, Mason H, et al. (1993) Relationship between markers of endothelial dysfunction, oxidant injury and tubular damage in patients with insulin dependent diabetes mellitus. Clin Sci 85: $557-562$

38. Chiarelli F, Marzio DD (2010) Diabetes Angiopathy in Children. HK J Paediatr 15:214-223.

39. Rudberg S, Osterby R (1998) Diabetic glomerulopathy in young IDDM patients. Preventive and diagnostic aspects. Horm Res 50: 17-22.

40. Kuzmic AC, Brkljacic B, Ivankovic D, Galesic K (2000) Doppler sonographic renal resistive index in healthy children. Eur Radiol 10: 1644-1648.

41. Ishimura E, Nishizawa Y, Kawagishi T, Okuno Y, Kogawa K, et al. (1997 ) Intrarenal haemodynamic abnormalities in diabetic nephropathy measured by duplex Doppler sonography. Kidney Int 51: 1920-1927.

42. Tublin ME, Bude RO, Platt JF (2003) The resistive index in renal doppler sonography: where do we stand? 180:885-892

43. Sperandeo M, D’Amico G, Variale A, Sperandeo G, Annese MA, et al. (1996) Pulsed wave color Doppler echography of the intrarenal vessels in patients with insulin-dependent diabetes mellitus and incipient nephropathy. Arch Ital Urol Androl 68: 183-187.

44. Hamano K, Nitta A, Ohtake T, Kobayashi S (2008) Associations of rena vascular resistance with albuminuria and other macroangiopathy in type 2 diabetic patients. Diabetes Care 31:1853-1857.

45. Ikee R, Kobayashi S, Hemmi N, Imakiire T, Kikuchi Y, et al. (2005)Correlation between the resistive index by Doppler ultrasound and kidney function and histology. Am J Kidney Dis 46:603-609.

46. Savino A, Pelliccia P, Schiavone C, Primavera A, Tumini S, et al. (2006) Serum and urinary Nitrites and Nitrates and Doppler Sonography in children with Diabetes. Diabetes Care 29: 2676-2681.

47. Tolins JP, Palmer RM, Moncada S, Raij L (1990) Role of endothelium-derived relaxing factor in regulation of renal hemodynamic responses. Am J Physio 258:H655-H662.

48. Pfeilschifter J (1995) Does nitric oxide, an inflammatory mediator of mesangia cells, have a role in diabetic nephropathy? Kidney Int 48:S50-S60.

49. Choi KC, Kim NH, An MR, Kang DG, Kim SW, et al. (1997) Alterations of intrarenal renin-angiotensin and nitric oxide systems in streptozotocin-induced diabetic rats. Kidney Int Suppl 60:S23-S27.

50. Soper CP, Barron JL, Hyer SL (1998) Long-term glycemic control directly correlates with glomerular filtration rate in early type 1 diabetes mellitus before the onset of microalbuminuria. Diabet Med 15:1010- 1014

51. Milovanceva-Popovska M, Dzikova S (2007) Progression of diabetic nephropathy :Value of intra-renal resistive index (RI). Prilozi 28: 69-79.

52. Kowluru RA, Abbas SN, Odenbach S (2004) Reversal of hyperglycemia and diabetic nephropathy: Effect of reinstitution of good metabolic control on oxidative stress in the kidney of diabetic rats. J Diabetes Complications 18 282-288.

53. Hamano K, Ai Nitta A Ohtake T, Kobayashi S (2008) Associations of Rena Vascular Resistance With Albuminuria and Other Macroangiopathy in Type 2 Diabetic Patients. Diabetes Care 31: 1853-1857.

54. Pelliccia P, Savino A ,Cecamore C, Primavera A, Schiavone C, et al. (2008) Early changes in renal hemodynamics in children with diabetes: Doppler sonographic findings. J Clin Ultrasound 36: 335-340. 